\title{
Exploring the beliefs of Australian prefabricated house builders
}

\author{
Dale A Steinhardt and Karen Manley \\ Queensland University of Technology, Australia
}

\begin{abstract}
The housing sector accounts for a majority of newly constructed buildings. Prefabrication, defined as the factory construction of houses or significant components, is widely promoted as a means to improve efficiency. This paper focuses on the research questions: RQ1. What are the attitudes of builders towards prefabrication adoption? RQ2. What types of stakeholders do builders believe influence their adoption decisions? RQ3. What types of contextual influences do builders believe impact their adoption decisions? Current prefabrication research has focused on the advantages and disadvantages of prefabrication, without further unpacking the beliefs of stakeholders that underpin them. This paper addresses this gap and increases the understanding of beliefs that can frame interventions to increase the market penetration of prefabrication. Fourteen interviews with Australian prefabricators were undertaken as a Belief Elicitation Study. This qualitative methodology is framed by the Theory of Planned Behaviour (TPB) and the Technology Acceptance Model (TAM). Results show that modern high-quality prefabricated housing has struggled to overcome historical stigma; improved construction speed has not and is not likely to translate to reduced totals costs for a majority of firms; and prefabrication adoption has been hindered by an almost completely unsupportive industry infrastructure. Recommendations are made to frame arguments in improving short-term outcomes for an industry driven by practical considerations. Future discourse must focus on cost impacts, financial security and risk reduction. Establishing networks of prefabricators that can build a strong, unified voice for the industry should be prioritised.
\end{abstract}

Keywords: Housing, prefabrication, Australia, beliefs, attitudes.

Paper type: Research article

\section{Introduction}

Australian and international data show housing accounts for $20 \%$ to $35 \%$ of all construction activity (Australian Bureau of Statistics, 2015; European Construction Industry Federation, 2014). The housing sector deserves a distinct focus as it is distinguished from the industrial and commercial sectors by a high level of client attachment to the project, fewer subcontractors, and a predominance of smaller construction firms (Costantino, Pietroforte and Hamill, 2001). There is significant unrealised potential for builders to drive housing innovation (Thorpe, Ryan and Charles, 2009), stemming from their central role in coordinating staff and subcontractors, and ultimately delivering a finished housing product to a client (Gann and Salter, 2000).

Prefabrication, referring to the creation of houses or significant housing components in a factory manufacturing environment, has been promoted widely in academia and industry as a means to improve the efficiency and sustainability of the housing industry (e.g.: Pan, Gibb and

\footnotetext{
Copyright: Construction Economics and Building 2016. (C) 2016 Dale Steinhardt and Karen Manley. This is an Open Access article distributed under the terms of the Creative Commons Attribution 4.0 Unported (CC BY 4.0) License (https://creativecommons.org/licenses/by/4.0/), allowing third parties to copy and redistribute the material in any medium or format and to remix, transform, and build upon the material for any purpose, even commercially, provided the original work is properly cited and states its license.
}

Citation: Steinhardt, D.A., and Manley, K. 2016. Exploring the belief of Australian prefabricated house builders, Construction Economics and Building, 16(2), 27-41. DOI: http://dx.doi.org/10.5130/AJCEB.v16i2.4741.

Corresponding author: Karen Manley; Email - k.manley@qut.edu.au

Publisher: University of Technology Sydney (UTS) ePress 
Dainty, 2007; Shahzad and Mbachu, 2013). Yet uptake has been slow. Formal data on prefabrication is not provided by the statistical agencies of many countries, including Australia. This forces a reliance on informal estimates. In Australia government-supported industry bodies such as the Construction and Property Services Industry Skills Council and the Manufacturing Excellence Taskforce of Australia have estimated a continuing low uptake of approximately 3$5 \%$ of all new construction and housing (Crough, 2015; The C. I. E., 2013). This paper examines the reasons underlying this low uptake by exploring house builders' beliefs about prefabrication.

\section{Background}

Large-scale changes to practices and culture in the modern construction industry are known to progress at a glacial pace (Saxon, 2001). Alshawi et al (2012) highlighted how construction firm owners are cognitively biased to ignore the value of innovations, instead relying on their established expertise which aligns closely to prevailing industry practice. Most firm-led innovation activity in the residential construction industry is subsequently minor changes to internal processes (Thorpe, Ryan and Charles, 2009). Regulators and government bodies have the potential to instigate larger changes, through top-down enforcement of standards and/or offering of incentives (Loosemore, 2014). Clune (2012) highlighted the difficulty in imposing top-down changes on construction firms, particularly when long-term policies clash with immediate priorities like housing production costs. Changes introduced at any level thus rely on grassroots industry support to ensure their success.

As noted in the introduction, prefabrication does not currently enjoy this support in Australia, and is working against an unsupportive backdrop. Gann and Salter (2000) present a model of this backdrop in the traditional (and still dominant) construction model. Onsite builders, along with architects and engineers, are placed as central intermediaries responsible for delivering houses to clients. Their role involves completing a discontinuous series of projects, engaging and disengaging with a network of stakeholders. These can be close influences, in the case of suppliers, clients or subcontracted trades; or more distant contextual influences such as regulators, policy makers or researchers (Jing, Qiping and Manfong, 2009). This network supports and reaffirms current industry practices of how construction should be done.

Early innovators face the challenge of committing to move ahead of industry norms, while still relying on the support of a system that incentivises business-as-usual. This commitment to innovation carries with it significant risk in challenging the inertia of the construction industry, but also potential for huge rewards in becoming an industry leader (Loosemore, 2014). The current paper is based on 14 interviews to examine house builders' experiences adopting prefabrication, with a particular focus on how the current views of the industry have affected their actions.

\section{Views on prefabrication}

Table 1 summarises a number of recent studies which have collected experiential qualitative data on issues relevant to adopting prefabrication. These studies have not always been focused on prefabricated housing specifically, but provide a starting point for further analysis. Table 1 does not represent a comprehensive list; instead the studies were selected by the authors based on their in-depth, qualitative nature, given the focus of the current study on perceptual data. The value of these studies lies in their ability to communicate insights and themes which reflect direct experiences. Such detailed observations are a key input to policy development (Richardson, 2012). 
Table 1: Recent in-depth studies of construction firms' views on prefabrication

\begin{tabular}{|c|c|c|c|}
\hline Study & e & 180 & Disadvantages \\
\hline $\begin{array}{l}\text { [G] } \\
\text { Goulding, } \\
\text { Rahimian, } \\
\text { Arif and } \\
\text { Sharp } \\
(2012)\end{array}$ & $\begin{array}{l}\text { h } \\
\text { ts, } \\
\text { es }\end{array}$ & \multirow{7}{*}{ 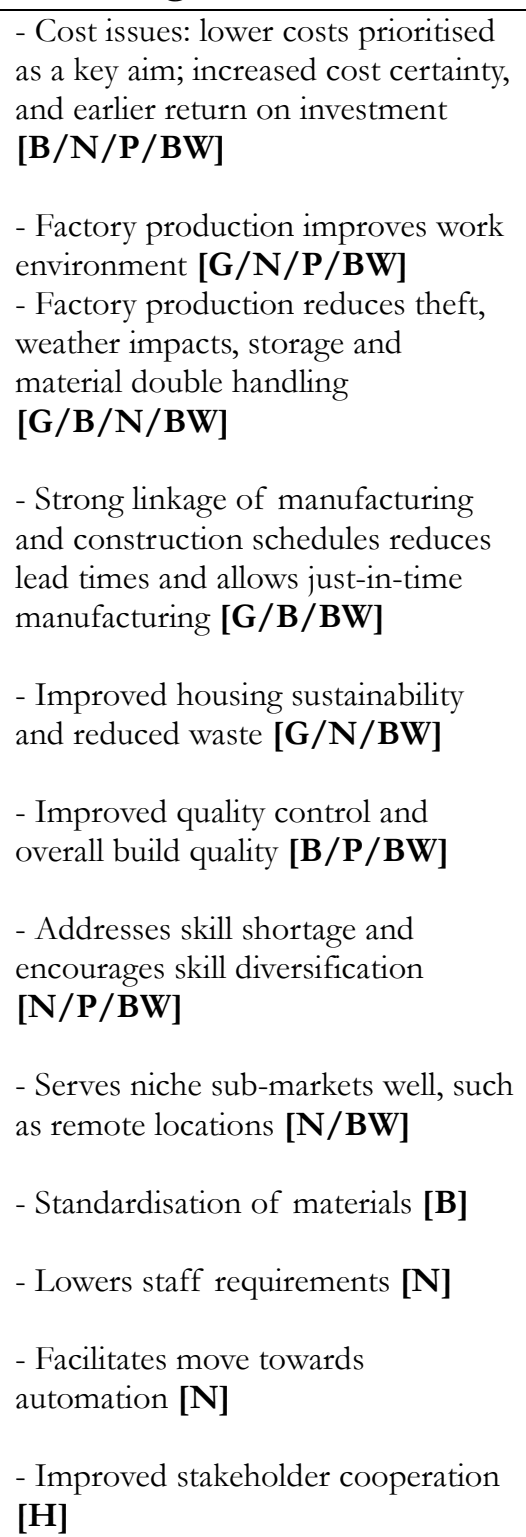 } & \multirow{7}{*}{$\begin{array}{l}\text { - Manufacturing standardisation } \\
\text { clashes with flexibility } \\
\text { [G/B/N/P/BW] } \\
\text { - Cost issues: High initial } \\
\text { development costs, and higher } \\
\text { selling costs [B/N/P/BW] } \\
\text { - Cultural industry resistance } \\
\text { [N/H/BW] } \\
\text { - Reliance on particular suppliers, } \\
\text { and possible monopoly creation if } \\
\text { limited availability [B/N/BW] } \\
\text { - Need to retrain or requalify staff } \\
\text { [G/N/BW] } \\
\text { - Large number of regulatory issues } \\
\text { [N/H/BW] } \\
\text { - Poor mainstream consumer } \\
\text { acceptance and lack of sufficient } \\
\text { demand [B/N/H] } \\
\text { - Process restructure required to } \\
\text { encourage integration [G/N] } \\
\text { - Increases number of actors and } \\
\text { process complexity [H/P] } \\
\text { - Automation not realistic or } \\
\text { developing [G/N] } \\
\text { - Necessary economies of scale not } \\
\text { present for advanced manufacturing } \\
\text { [N/P] }\end{array}$} \\
\hline $\begin{array}{l}\text { [B] } \\
\text { Bildsten } \\
(2011)\end{array}$ & , & & \\
\hline Gouldi & $\begin{array}{l}\text { stakeholders in } \\
\text { Germany, Sweden, } \\
\text { the Netherlands and } \\
\text { the UK. }\end{array}$ & & \\
\hline $\begin{array}{l}{[\mathbf{B W}]} \\
\text { Blisma } \\
\text { Wakefi } \\
(2009)\end{array}$ & n & & \\
\hline $\begin{array}{l}\text { and Reyme } \\
\text { 2008) }\end{array}$ & $\begin{array}{l}g^{\prime} \\
\text { rs }\end{array}$ & & \\
\hline P] & & & \\
\hline (2007) & $\begin{array}{l}\text { sing } \\
\text { (face-to- } \\
\text { a postal }\end{array}$ & & \\
\hline
\end{tabular}

These studies have identified issues primarily in UK and European contexts. The unique challenges of prefabrication in the Australian housing sector have not been a focus of previous studies. Blismas and Wakefield's (2009) Australian study provided some initial evidence, but considered the residential and non-residential sectors together. While each of these qualitative studies has identified a broad range of disadvantages and advantages involving different stakeholders and influences, there has been little attempt to place this research within a structured theoretical framework that can guide intervention development. Broad categorisations like 'drivers/barriers' (Bildsten, 2011; Blismas and Wakefield, 2009; Pan, Gibb and Dainty, 2007) or 'opportunities/limitations/external constraints' (Hofman, Voordijk and Halman, 2009) and arbitrary thematic typologies such as 'People, Process, Product, Technology, Market' (Goulding et al., 2012; Nadim and Goulding, 2011) have been employed. In contrast, analysis in the current study is driven by well-accepted theory that provides a depth missing from previous analysis. Nevertheless, previous studies have consistently indicated that the adoption of prefabricated construction requires a paradigm shift encompassing multiple levels of intervention. 
The potential disadvantages of prefabrication identified in Table 1 can thus be countered with actions at various levels. For instance, technical engineering and design input is needed to ensure that standardised manufacturing allows flexible construction output. Relationships with upstream suppliers must be managed by builders to reduce business risk. Tradespeople need to be offered training to learn to use new prefabrication technologies. Government agencies have a key role in shaping the regulatory environment that can support prefabricated methodologies. Consumers must also ultimately be convinced of prefabrication's benefits to drive demand. Prefabrication adoption can theoretically be driven by changes directed at any of these levels.

\section{Builder focus}

Four of the six key studies above (Blismas and Wakefield, 2009; Goulding et al., 2012; Halman, Voordijk and Reymen, 2008; Nadim and Goulding, 2011) solicited opinions from a range of stakeholders including builders, material suppliers, designers and academics, without consideration of their unique perspectives or biases. These broad exploratory studies must now be built upon by more targeted and structured investigations. None of the previous studies cited above have looked at belief systems. Instead, earlier work has provided a relatively superficial examination of the advantages and disadvantages of prefabrication. Beliefs have not been categorised according to a structured theoretical base, and the influence of current industry context have not been considered. The current paper fills this gap by providing a more finely grained analysis of innovation determinants, by splitting them into belief categories comprising (1) perceived usefulness, (2) perceived ease of use (3) influence of stakeholders, and (4) broad context. This is a useful approach because such beliefs have been consistently shown to drive behaviour (Armitage and Conner, 2001). This work thus focuses on the following research questions:

RQ1. What are the attitudes of builders towards prefabrication adoption?

RQ2. What types of stakeholders do builders believe influence their adoption decisions?

RQ3. What types of contextual influences do builders believe impact their adoption decisions?

\section{Theoretical approach}

As there is no definitive structure or statistical tests that are universally accepted for qualitative research, an a priori theoretical model should be applied (Gephart, 2004). The widely-used Theory of Planned Behaviour (TPB, Ajzen, 1991) was chosen to frame the current study because it is has been repeatedly validated as a useful tool for exploring behaviour in diverse industries and jurisdictions (See Ajzen, 2011, for a summary of previous reviews). The TPB is a social psychology theory which posits that planned behaviours, such as a firm's adoption of prefabrication innovations, result from forming an intention to commit that behaviour. These intentions are in turn predicted by beliefs about attitudes, subjective norms ( $\mathrm{SN}$ ), and perceived behavioural control (PBC). Attitude refers to evaluation of the elements of the behaviour; subjective norm to key persons' approval of committing the behaviour; and PBC to the level of opportunity to commit the behaviour. The TPB thus provides a framework to explore intra-firm perceptual issues towards prefabrication (attitudes), the influence of the views of wider industry stakeholders including clients and suppliers (subjective norm), and wider contextual factors which may limit firms' opportunities to innovate (perceived behavioural control). A qualitative Belief Elicitation Study is recommended by the TPB's author (Ajzen, 2006) to provide a finelygrained understanding of the determinants of behaviour.

The current study also draws upon the work of Davis' (1985) Technology Acceptance Model (TAM). The TAM introduces two further constructs aligned to the attitude construct of the TPB: the perceived usefulness (PU) and perceived ease of use (PEoU) of a new technology. The 
theoretical and predictive validity of these constructs has been established across a range of disciplines (Bagozzi, 2007). PU is underpinned by the quality of outputs associated with the new technology, the resulting image of adopters, and the effect on complexity and efficiency of processes. Perceived ease of use is underpinned by the level of frustration and ease with which new technologies can be adopted (Venkatesh and Bala, 2008). PEoU is tied theoretically to the perceived capabilities of the firm to facilitate adoption, as the construct was originally built on the concept of individual self-efficacy (or belief in capacity to undertake a behaviour) (Davis, 1989). This novel combination of the TPB and the TAM as a single theoretical model (Figure 1) is appropriate to exploring house builders' beliefs as it captures intra-firm process and technical issues, as well as industry-wide socio-contextual influences.

TAM

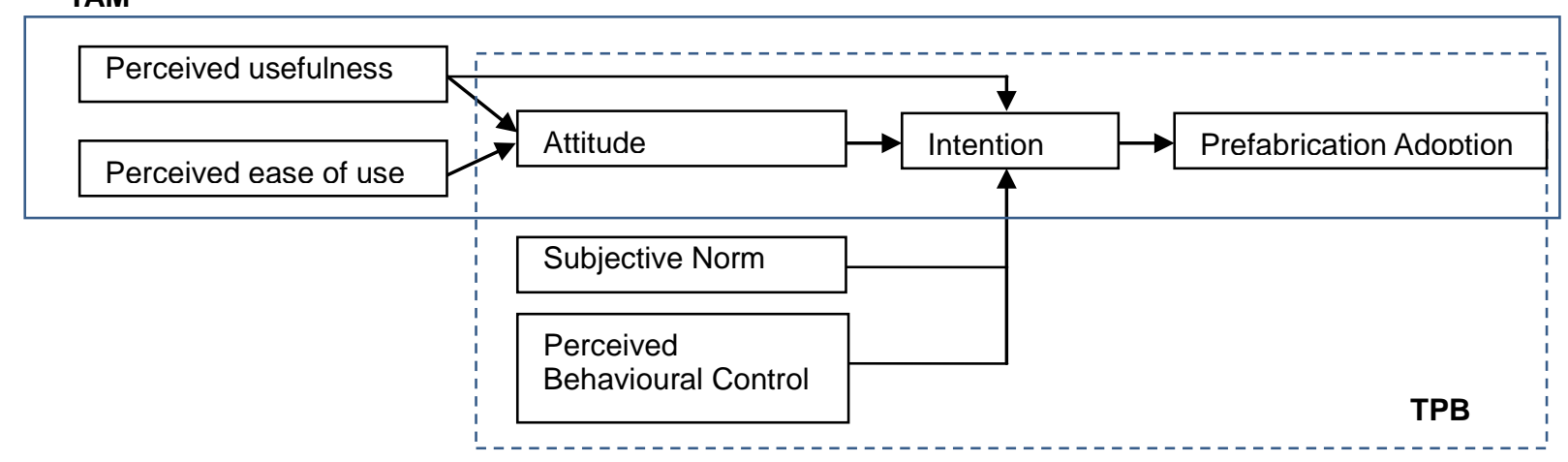

Figure 1: Combined TPB and TAM model for predicting prefabrication use in house building

\section{Method}

This is a Belief Elicitation Study as described above. The scope of prefabrication considered in this study was based on previous work defining a prefabrication continuum (Gibb and Isack, 2003), and includes both volumetric, fully-complete houses, housing modules (e.g. sections of a house, bathroom pods), and prefabricated structural panels used in onsite construction (e.g. structural insulated panels, precast concrete). The use of smaller, non-structural component subassemblies were not considered within the scope of the current research as they are highly represented in traditional building and unlikely to promote the same advantages as higher levels of prefabrication.

The current study had three primary aims to address the research question:

1. To derive a set of belief factors corresponding to the combined TPB and TAM predictors of intentions to adopt the innovation of prefabricated housing. Namely:

a. Attitudes

b. Normative influences

c. Behavioural control factors

2. To identify the most frequently cited belief factors identified in 1)

3. To describe and discuss the specific nature of these belief factors through analysis of qualitative interview transcript data.

This final aim was more exploratory in nature, drawing on social science methods to illuminate and contextualise the data collected to address the first two aims. The study involved 14 interviews with senior representatives of builders representing Australia's most advanced and significant prefabricators, as indicated by the sophistication of their operations. Table 2 shows the type of prefabrication undertaken by the early-adopter interviewees. On the basis of a previously defined prefabrication continuum (Gibb and Isack, 2003), only builders using 
volumetric (e.g. house modules, bathroom pods) or prefabricated structural panels (e.g. structural insulated panels [SIP] were considered for interview. Firms employing other sub-assemblies like trusses were not included as they are relatively common and not representative of high-level prefabrication innovators.

Table 2: Interview participants by type of prefabrication $(\mathrm{N}=14)$

\begin{tabular}{ll}
\hline Prefabrication Type & $\mathbf{n}$ \\
\hline Complete/Modular & 7 \\
Panel (insulated) & 5 \\
Complete/Modular/Pods & 2 \\
\hline
\end{tabular}

The 14 firms covered in the study were all small or medium sized builders from the Australian states of WA and Queensland as these states have large mining sectors that drive the majority of prefabrication activity in Australia. Interviews were conducted for seven builders in each of these two jurisdictions during 2014. Interview details are shown in Table 3.

Table 3: Interview Schedule ( $=14)$

\begin{tabular}{|c|c|c|c|}
\hline $\begin{array}{l}\text { Interviewee } \\
\text { Identifier }\end{array}$ & Interviewee Title & Location & $\begin{array}{l}\text { Interview } \\
\text { Type }\end{array}$ \\
\hline $\mathbf{A}$ & Chief Operating Officer & $\begin{array}{l}\text { Toowoomba, } \\
\text { Queensland }\end{array}$ & Phone \\
\hline B & Director & $\begin{array}{l}\text { Maddington, Western } \\
\text { Australia }\end{array}$ & Phone \\
\hline C & Senior Manager & $\begin{array}{l}\text { Perth, Western } \\
\text { Australia }\end{array}$ & Phone \\
\hline D & Chief Executive Officer & $\begin{array}{l}\text { Perth, Western } \\
\text { Australia }\end{array}$ & Phone \\
\hline $\mathbf{E}$ & Director & $\begin{array}{l}\text { Albany, Western } \\
\text { Australia }\end{array}$ & Phone \\
\hline $\mathbf{F}$ & Senior Manager & $\begin{array}{l}\text { Perth, Western } \\
\text { Australia }\end{array}$ & Phone \\
\hline G & Company Accountant & $\begin{array}{l}\text { Springwood, } \\
\text { Queensland }\end{array}$ & Phone \\
\hline $\mathbf{H}$ & Chief Executive Officer & Noosaville, Queensland & Phone \\
\hline I & Manager & $\begin{array}{l}\text { Deception Bay, } \\
\text { Queensland }\end{array}$ & On site \\
\hline $\mathbf{J}$ & Director & Yandina, Queensland & Phone \\
\hline K & Director & $\begin{array}{l}\text { Cockburn, Western } \\
\text { Australia }\end{array}$ & Phone \\
\hline $\mathbf{L}$ & Senior Manager & $\begin{array}{l}\text { Wangara, Western } \\
\text { Australia }\end{array}$ & Phone \\
\hline $\mathbf{M}$ & $\begin{array}{l}\text { Sales and Marketing } \\
\text { Manager }\end{array}$ & $\begin{array}{l}\text { Caboolture, } \\
\text { Queensland }\end{array}$ & Phone \\
\hline $\mathbf{N}$ & Director & Crestmead, Queensland & On site \\
\hline
\end{tabular}

Interviews were generally conducted over the phone to fit with the busy schedules of respondents, except for two conducted in-person. Interviews ran for an average of 60 minutes. Recordings of the interviews were transcribed verbatim by the interviewer within 48 hours. Participants were asked a series of questions in a semi-structured format as defined by Ajzen's (2002) guidelines for TPB elicitation studies. The questions covered overall attitudes towards prefabricated housing (general advantages and disadvantages of its use, perceived usefulness [e.g. its effects on housing quality, building efficiency], perceived ease of use [e.g. complexity of 
building, frustrations associated with its use]), subjective norm (e.g. level of support for using prefabrication from key people), and perceived behavioural control (e.g. influences of contextual factors on prefabrication use such as regulations and codes; level of autonomy to choose to use prefabrication). Interviews continued until the point of data saturation, where additional data resulted in minimal new information.

The previous qualitative studies exploring prefabrication have suffered from presenting reductionist conclusions or tabulations without allowing participants' views to be expressed in their own words. A middle-point between numerical and textual analysis lies in the use of numerical count data to reassure readers valid data has not been overlooked; supplemented by highlights of 'raw or primary qualitative data' (Gephart, 2004, p.460). A thematic analysis process was thus used to analyse electronic transcripts of the interview data, grouping and counting segments of text responses under at least one of the categories proposed by the TPB/TAM model. These counts were then built upon through representative quotes. This process follows Bluhm et al's (2010) best practice guide for qualitative studies through counting the 'countable' themes, giving voice to participants through quotes, combining numeric and text analysis, and relying on a strong theoretical foundation.

\section{Results and discussion}

The results of the analysis are presented corresponding to each of the theoretical components of the combined TPB and TAM model in Figure 2. The frequency with which factors were mentioned is presented in Table 4.

These beliefs have been mentioned in a piecemeal fashion in previous literature, but they have never before been brought together in a comprehensive linked system. This suggests firstly, that the current study presents a well validated set of organised beliefs, and secondly, that value is added by using a robust framework for interpreting the relationships between beliefs. These outcomes have important policy implications. For example, the disaggregation of advantages/disadvantages into 'perceived usefulness'/'perceived ease-of-use' points to the difference between outcome determinants and process determinants respectively. If businesses cannot effectively manage the processes supporting use, then the benefits of use become immaterial. Hence policy attention is directed to assisting businesses with determinants A7/8 and $\mathrm{D} 5 / 6 / 7 / 8$.

Similarly, the distinction between normative influences and perceived behavioural control points to the different roles of stakeholders, versus contextual factors respectively. Stakeholder beliefs may be best dealt with through educational interventions, while context might be best influenced through changes to macro-economic settings and institutional arrangements.

Table 4 responds to the three research questions driving the study. Firstly, builders' attitudes to technology acceptance have been revealed, responding to RQ1. Secondly, the types of stakeholders builders believe influence their adoption decisions have been revealed (normative influences) responding to RQ2. Thirdly, the types of contextual influences that builders believe impact their adoption decisions have been revealed (behavioural control factors), responding to RQ3.

The theoretical rigor of the current approach, which sets this study apart, gives rise to a more sophisticated analysis of how identified issues relate to one another, compared to previous studies. The current study highlights that the advantages and disadvantages of prefabrication are not the sole determinant of adoption; instead adoption is also influenced by the builders' beliefs about the current state of the industry as reflected in influential stakeholders and contextual factors. The next section summarises the main themes picked up by the current study. The quotes shown represent the views of all 14 interviewees. 
Table 4: Tabulation of reported TPB/TAM beliefs

\section{Attitudes to Technology Acceptance}

\section{Perceived Usefulness}

(A1) Better quality to many traditional builds

14 (D1) Inability to reduce project costs 12

(A2) Cost-effective niche applications

(A3) Improved speed of construction

9 (D2) Non-traditional designs 11

(A4) Improved energy efficiency post-occupation

9 (D3) Historical image of poor quality output

(A5) Reduced construction waste

4 (D4) Increased post-occupation maintenance

(A6) Improved workplace safety

Perceived Ease of Use

(A7) Improved coordination of staff and tasks

(A8) Simplification of tasks

9 (D5) Increased transport logistics 8

3 (D6) Risks in adapting to new processes 8

(D7) Greater preparatory work requirements 7

(D8) Difficultly aligning to traditional designs 7

\begin{tabular}{llr}
\hline Normative influences & n Behavioural control factors & $\mathbf{n}$ \\
\hline Trades and subcontractors & 14 Competitive viability & 12 \\
Consumers & 11 Financing support & 9 \\
Government and regulatory bodies & 10 Government and regulatory support & 8 \\
Finance industry / banks & 9 Macroeconomic conditions & 5 \\
Suppliers & 7 Energy efficiency requirements & 4 \\
Industry representative bodies & 6 Labour and skills availability & 3 \\
Architects and designers & 4 Climate change & 2 \\
Developers & 3 & \\
Engineers & 3 & \\
\end{tabular}

\section{Reinforcement of main themes}

Prefabrication's increased construction speed was widely acknowledged as an inherent advantage, particularly in preventing time lost due to weather delays. Its ability to simplify construction processes was also commonly recognised, whether stemming from onsite use of structural panels, or factory-based process coordination. This factory-control and industrialisation was also perceived as improving the environmental performance of housing compared to traditional methods. The high establishment cost for factory-based operations was however a major disadvantage, especially compared to the minimal outlay required to establish traditional residential construction firms. The technical and bureaucratic challenges of transporting large prefabricated structures additionally contributed to eroding efficiencies gained elsewhere in the manufacturing or building process.

Prefabrication's success in niche rural Australian markets (Blismas and Wakefield, 2009) was highlighted, stemming from the ability to ship completed houses from well-resourced urban locations to rural locations not otherwise serviced in a timely fashion. Despite these successes, perceptions of prefabrication as low-quality, cheap and ugly permeated the industry. Lack of clear support from the architectural and building design sub-industries continued to manifest in difficulties tying prefabrication's standardisation to mainstream design sensibilities. The inertia of traditional trade resistance to both factory-based or panellised forms of prefabrication was also commonly acknowledged. These issues have been previously emphasised in the literature and their continued presence in the Australian housing industry suggests they are yet to be resolved. The current findings therefore suggest the need for more urgent policy action. Attention is turned now to exploring three important trade-offs among the determinants of adoption that have not been emphasised in previous literature. 


\section{TAM - Attitudes}

\section{Modern quality versus historical stigma}

All of the interviewed early-adopters believed the houses or components they produced were of a better quality than traditional builds. Deliberate effort was made to draw distance from the historically low-cost, low-quality market:

"I think we have a very good image. People see that we are architecturally focused, and we are about style... There's plenty of modular construction out there, and it has been for years. It's probably served mining - it's the donga-type, it's the portable. People can clearly differentiate between the two these days." Interviewee $D$

This emerging focus on architectural design and quality has been anecdotally noted as a unique selling point of leading prefabricated housing firms in the Australian industry, in contrast to the focus on performance engineering in international leaders like Japan and Germany (Aitchison, 2014). The gap between these leading firms and the overall prefabricated industry was however acknowledged.

Conflict thus still exists between efforts from early innovators to redefine the prefabricated housing industry, against the inertia of widely-accepted historical stigma. This comment also hints at the long time-scale which may need to elapse for prefabrication to prove to the market it is as durable as the established traditional housing products. The current Australian context for prefabrication innovators is likely to however be what Barrett and Sexton (2006) refer to as a 'constraining interaction environment.' Innovation activity is concentrated on short-term success, with a lack of resources to consider long-term market positioning.

\section{Increased speed vs. unclear cost benefits}

While prefabrication's ability to increase construction speed was readily acknowledged, this was critically not easily translated to reductions in overall project costs. Total cost reductions for early-adopters may rather be dependent on increased turnover:

"The compelling reason you should, even though it doesn't save you any money on a job basis, if you can knock 20 days of labour off a job out of 120 man days of labour, ...you can, providing you've got the sales, start more projects in a year." Interviewee I

This 'theoretical lowering of cost was routinely juxtaposed against the realities of small and medium firms to scale or redirect their business interests. This places prefabricators in a potentially awkward position of being reliant on continued sales and support from a conservative housing market consisting of irregular clients that favour the lowest possible unit price above all other factors. It also renders one of prefabrication's most recognised advantages as not realistically advantageous. This may effectively set a baseline firm size required to make prefabricated housing viable in Australia, as has been noted for construction innovation generally (Loosemore, 2014). This is particularly aberrant against the backdrop of the Australian housing industry's dominance of small and medium sized firms.

\section{Process coordination vs. increased risk and effort}

Early-adopter firms reported challenges finding the time, funds and administrative support to prototype and implement new prefabricated building systems. The promised long-term benefits could not be realised without the support of the wider industry during the lengthy development process. 
"To take the panels out to random builders is a very costly exercise. Because for a builder to take on one of these types of builds ad hoc... they're going through the same learning curve that we've been going through. That's why we made the conscious decision... to dedicate to this system until we actually got it right." Interviewee F

Early-adopters are faced with devoting extra time and capital investment to a risky business prospect that is not supported by an inertial wider ecosystem. A supportive industry network of competencies is known to compensate for limitations yet to develop in an innovating firm (Ritter and Gemunden, 2004). The ability of a firm to either draw on internal resources or make these supportive linkages is likely to be a strong determinant of their ability to survive as early innovators.

The study also provides new insights into the roles played by stakeholders and context, as described in the following two sections.

\section{Subjective norm}

Table 4 lists the stakeholders (subjective norm) identified by respondents as key normative influences on prefabrication adoption. Such stakeholders were likely to either be actively resistant or indifferent to adoption. Negative views were however perceived as rooted in valid practical considerations like the lack of a compelling business case for a shift to prefabrication:

"There are certain trades that just want to turn up and keep doing what they've been doing for the last 15 to 20 years. And it's a no brainer for them - they just keep doing it, and they're already earning good money." Interviewsee F

Small pockets of strong industry support were identified among the general population of tradespeople. These people were seen to highly value particular lifestyle factors such as the consistency of factory work, certainty of work locations, and absence of fly-in-fly-out schedules. These findings suggest that appealing to universal concerns like convenience is central to encouraging rapid change.

"They come to the same site every time, there's facilities onsite [at the factory]. There's workplace health and safety in place, there's organisation, there's management or supervision there on the site. They think it's absolutely terrific." Interviewee J

Firms, tradespeople, architects or any other stakeholders successfully engaged in traditional build methods would be unlikely to abandon their current business model and partnerships unless they sense a shift in the industry that would threaten or improve their income security.

"In the early stages it's hard to get anyone interested in dealing with you too much. But as the work picks up, you get a little more loyalty from them" Interviewsee $K$

"[Change won't happen] until alternative methods of construction absorbs itself into the industry and becomes more approachable for trades. Also, the tightening of the industry - when a lot of the fixing trades aren't flush with work, they find another hat to put on and say 'yes, I'm interested now.' It'll be a combination of those two influences" Interviewee $F$

Only well-resourced or risk-accepting housing firms are likely to be convinced to make this leapof-faith (Hughes et al., 2006). Pay and job security are considered 'hygiene factors' (Herzberg, 2003), or basic requirements for a successful work environment, and should be given due consideration when promoting a shift to prefabrication. 


\section{Perceived Behavioural Control}

Table 4 shows the contextual factors (perceived behavioural control) that respondents felt influenced adoption. There was a general belief that prefabrication does not yet have a critical mass of support from the wider industry. Responses to the behavioural control questions predominantly revolved around several major contextual factors affecting builders' opportunities to adopt prefabrication.

\section{Competitive viability and macroeconomic conditions}

The competitive nature of the housing industry was seen as a significant source of pressure, with one interviewee bluntly noting that if prefabricators can't compete, they 'don't have a place in the marketplace.' The interviewees did not perceive any differentially negative pressure of macroeconomic changes like the Global Financial Crisis on the prefabricated housing sector; though acknowledged that it did cumulatively add to their existing burden in competing against the mainstream housing market. It was also acknowledged that improved methods of construction have not been a sufficient drawcard to a housing market driven by nonconstruction factors like amenity, location and resale value (cf. Eves and Kippes, 2010).

"The priority for them is more about living space, and the lifestyle factors associated. Accessibility to infrastructure, walking... They are more interested in the space than the built product." Interviewee I

This is analogous to the earlier discussions regarding alignment of prefabrication development to the perspective of the wider housing industry. While technological development and engineering advances may be the underlying drivers of prefabrication's success, consumer priorities must take ascendancy. The niche success of prefabrication for rural housing highlights the potential success of this client-centred approach on a small scale. Identifying unique niches of demand for urban prefabricated housing however remains a challenge.

\section{Financial support}

A majority of interviewees identified a lack of support from the financial sector for prefabricated housing. Traditional financing involving progress payments tied to onsite build milestones was not routinely feasible. This lead to firms having to internally finance entire projects until manufacturing was complete, rendering large-scale projects prohibitively expensive for all but the most successful firms. Respondents pointed to a lack of political will for regulatory authorities to compel banks to change (“Why would they?'). The high profitability of Australia's major lenders in the traditional housing market was also seen as a major deterrent to expanding their interests. This remains a central roadblock to reform, particularly given the existing power imbalance between banks and most prefabricated innovators.

\section{Government and regulatory support}

Several issues involving governments and their regulatory activities were raised. Government housing tenders were criticised by interviewees for their short-sighted criteria that limited opportunities for prefabrication firms. They perceived that tenders favoured firms that produced traditional housing, had existing government relationships, and could produce high volumes of relatively low-cost builds using established methods. Changes to long-established regulations were also proposed as potential drivers of prefabrication. The well-accepted change to extend Queensland's onsite-only Home Warranty Insurance scheme to cover prefabricated builds (Department of Housing and Public Works, 2013) was seen as an example of how burdens could be removed, while simultaneously adding further scrutiny to the workmanship of 'shonky' prefabricated builders. 


\section{Climate change and energy efficiency requirements}

Reform of regulations concerning energy efficiency and sustainability were raised by several interviewees, in line with growing academic interest in house buyers' concerns with these issues (Johnston, Guaralda and Sawang, 2014). The long-term impacts of climate change, rising electricity costs and extreme weather events were all suggested as supportive factors for prefabrication uptake. The improved seal and insulation of prefabricated housing was commonly noted. The ability of the National Construction Code to set stricter 'star-rating' performance targets was seen as a potential driver to making prefabricated systems more cost competitive.

\section{"If we got to seven stars, [prefabricated] systems like this would dominate. Traditional, old fashioned, brick construction, to genuinely get to seven stars, would not be cost effective" Interviewee L}

The introduction of such changes will be impacted by the will of the current housing industry to disturb the status quo. As Clune et al. (2012, p.658) note: "increases in minimum mandated efficiency ratings have historically been robustly contested" on the grounds of reduced housing affordability. Such debates have thus typically rewarded inefficient traditional builders on the basis of appealing to immediate consumer priorities, rather than long-term industry planning.

\section{Labour and skills availability}

The challenge of an ageing workforce and a reduction in qualified traditional tradespeople was raised as a positive influence on increased prefabrication adoption. The current lack of specific skills training and readily available trades with prefabrication experience was however noted as a burden to fund and administer without high-level support from government departments or industry bodies.

"If you can get an apprenticeship as a painter then you should be able to get an apprenticeship as a thermal panel carpenter. ... But it's the sort of thing you just can't constantly personally fund." Interviewee $F$

As this formal network of skilled trades and educators is still developing, support from elsewhere, must be sought. Connections between individual prefabrication firms and localised networks of known skilled employees may be able to partially fill this role. A well-resourced and neutral body, not influenced by individual firm priorities, will however be required for long-term industry development.

\section{Conclusions}

The current paper provides in-depth data on the perceptions of Australian builders towards prefabrication. Attitudes were found to be mixed, with no dominant position emerging, while their perceptions of the current state of prefabrication in Australian housing, as reflected in the influence of key stakeholders and contextual actors, could be described as promising, and moving forward slowly despite a problematic stakeholder network and industrial context.

This is not surprising given the well-established inertia of construction industry practice. While builders and their firms were the focal point of data collection for this paper, their reported experiences are shaped by the wider industry in which they exist. Broadly acknowledged technical benefits like prefabrication's increased construction speed have not been sufficient to shift the housing industry towards wide-spread adoption. Fears of increased costs or business risk underpin beliefs industry-wide.

The current paper has identified several examples of shortfalls between prefabrication's promise and actual improvement in housing construction practice. The reality of modern high-quality 
prefabricated housing battles against a historical stigma of the 'donga'; construction speed has not and is not likely to translate to reduced costs for a majority of firms; and prefabrication adoption is difficult to realise with an almost completely unsupportive industry infrastructure. Developing a supportive network of stakeholders and institutions may take time, but strategic and achievable priorities need to be established.

As noted in the introduction, individual firms are typically unable to exert significant influence to change an industry, and must rely on channelling their energies through higher-order influences. Groups such as Australia's peak body for prefabrication, prefabAUS, and the recently announced ARC Training Centre for Advanced Manufacturing of Prefabricated Housing are developing. They may serve a valuable role in connecting like-minded firms, collating experiences and resources, and framing persuasive arguments for change that carry weight with higher order bodies.

To be successful, these arguments must have a dual focus on long-term goals, couched in improving short-term outcomes for an industry driven by practical considerations like income and project costs. This necessitates framing messages and actions in the dominant industry discourse of costs, security and reducing risks. It is not enough for example, to promote improved energy efficiency as an ideological goal, at the cost of increased house prices. Prices must be reduced by improved energy efficiency, and immediately so. Failure to meet these goals signals a likely failure of prefabrication innovations to gain market share.

Shifting the opinions of large institutions like banks and government departments may be particularly challenging, so networks of prefabrication firms must leverage their combined wills to encourage any feasible change. Once small proof-of-concept and demonstration projects can be established that satisfy minimal risk for firms and banks alike, this may provide a short-term foot-in-the-door to facilitate larger, long-term project development.

\section{Limitations and future research}

The TPB/TAM model employed in the current study covered a range of influences from immediate technical advantages and disadvantages, to the influence of important others, to contextual factors limiting possible courses of action. The breadth of the theory is both a weakness and strength. It allows identification of a wide range of important influences but these may not necessarily form a coherent model without further quantification and testing. Further publications will expand and statistically verify the proposed relationship between the predictors identified in this study and intentions to adopt prefabricated housing innovations. It is normal for a Belief Elicitation Study, such as presented here, to be conducted first in order to provide direction for a following quantitative study under TPB.

Finally, the focus on builders has precluded a comprehensive examination of the impact of their relationships on the adoption of prefabrication. The focus on relationships would provide a very fruitful avenue of future research as, of course, relationships within the supply chain and with support infrastructure, like regulators and technical support providers, are critical to adoption of new technologies, like prefabricated housing. A new theoretical approach would be required to canvass a more diverse range of views and opinions.

\section{References}

Aitchison, M., 2014. 20 shades of beige: lessons from Japanese prefab housing [online]. Available at: http:/ / theconversation.com/20-shades-of-beige-lessons-from-japanese-prefab-housing-31101.

Ajzen, I., 1991. The theory of planned behavior. Theories of Cognitive Self-Regulation, 50(2), pp.179-211. doi: http://dx.doi.org/10.1016/0749-5978(91)90020-t

Ajzen, I., 2002. Constructing A Theory of Planned Behavior Questionnaire [online]. Available at: http://people.umass.edu/aizen/pdf/tpb.measurement.pdf.

Ajzen, I., 2006. Behavioral Interventions Based on the Theory of Planned Behavior [online]. Available at: 
http://people.umass.edu/aizen/pdf/tpb.intervention.pdf.

Ajzen, I., 2011. The theory of planned behaviour: Reactions and reflections. Psychology \& Health, 26(9), pp.1113-27. doi: http://dx.doi.org/10.1080/08870446.2011.613995

Alshawi, M., Goulding, J., Engström, S. and Hedgren, E., 2012. Sustaining inertia? Construction clients' decisionmaking and information-processing approach to industrialized building innovations. Construction Innovation, 12(4), pp.393-413. doi: http://dx.doi.org/10.1108/14714171211272180

Armitage, C.J. and Conner, M., 2001. Efficacy of the Theory of Planned Behaviour: A meta-analytic review. British Journal of Social Psychology, 40(4), pp.471-99. doi: http://dx.doi.org/10.1348/014466601164939

Australian Bureau of Statistics, 2015. 8755.0 - Construction Work Done, Australia, Preliminary, Dec 2014. ABS. Canberra.

Bagozzi, R.P., 2007. The legacy of the Technology Acceptance Model and a proposal for a paradigm shift. Journal of the Association for Information Systems, 8(4), p.3.

Barrett, P. and Sexton, M., 2006. Innovation in Small, Project-Based Construction Firms*. British Journal of Management, 17(4), pp.331-46. doi: http://dx.doi.org/10.1111/j.1467-8551.2005.00461.x

Bildsten, L., 2011.

Blismas, N. and Wakefield, R., 2009. Drivers, constraints and the future of offsite manufacture in Australia. Construction Innovation: Information, Process, Management, 9(1), pp.72-83.

Bluhm, D.J., Harman, W., Lee, T.W. and Mitchell, T.R., 2010. Qualitative research in management: a decade of progress. Journal of Management Studies, 48, pp.1-26.

Clune, S., Morrissey, J. and Moore, T., 2012. Size matters: House size and thermal efficiency as policy strategies to reduce net emissions of new developments. Energy Policy, 48, pp.657-67. doi: http://dx.doi.org/10.1016/j.enpol.2012.05.072

Costantino, N., Pietroforte, R. and Hamill, P., 2001. Subcontracting in commerical and residential construction: an empirical investigation. Construction Management \& Economics, 19, pp.439-47. doi: http://dx.doi.org/10.1080/01446190010020390

Crough, D., 2015. Key findings from the Manufacturing Excellence Taskforce Australia. In: prefabAUS 2015 Conference: Industry Transformation. Melbourne.

Davis, F.D., 1985. A technology acceptance model for empirically testing new end-user information systems: Theory and results. PhD, Sloan School of Management, Massachusetts Institute of Technology.

Davis, F.D., 1989. Perceived usefulness, perceived ease of use, and user acceptance of information technology. MIS quarterly, pp.319-40. doi: http://dx.doi.org/10.2307/249008

Department of Housing and Public Works, 2013. Queensland Government Response to the Transport, Housing and Local Government Committee: Inquiry into the Operation and Performance of the Queensland Building Services Authority. Department of Housing and Public Works. Brisbane.

European Construction Industry Federation, 2014. Key Figures, Activity 2013. Brussels. FIEC.

Eves, C. and Kippes, S., 2010. Public awareness of "green" and "energy efficient" residential property: An empirical survey based on data from New Zealand. Property Management, 28(3), pp.193-208. doi: http://dx.doi.org/10.1108/02637471011051327

Gann, D.M. and Salter, A.J., 2000. Innovation in project-based, service-enhanced firms: the construction of complex products and systems. Research Policy, 29(7-8), pp.955-72. doi: http://dx.doi.org/10.1016/S0048-7333(00)001141

Gephart, R.P., 2004. From the editors: qualitative research and the 'Academy of Management Journal'. Academy of Management Journal, 47, pp.454-62.

Gibb, A.G.F. and Isack, F., 2003. Re-engineering through pre-assembly: client expectations and drivers. Building Research \& Information, 31(2), pp.146-60. doi: http://dx.doi.org/10.1080/09613210302000

Goulding, J., Rahimian, F.P., Arif, M. and Sharp, M., 2012. Offsite construction: strategic priorities for shaping the future research agenda. Architectoni.ca, 1, pp.62-73.

Halman, J.I.M., Voordijk, J.T. and Reymen, I.M.M.J., 2008. Modular Approaches in Dutch House Building: An Exploratory Survey. Housing Studies, 23(5), pp.781-99. doi: http://dx.doi.org/10.1080/02673030802293208

Herzberg, F., 2003. One more time: How do you motivate employees? Harvard Business Review, 81(1), pp.87-96.

Hofman, E., Voordijk, H. and Halman, J., 2009. Matching supply networks to a modular product architecture in the house-building industry. Building Research \& Information, 37(1), pp.31-42. doi: http://dx.doi.org/10.1080/09613210802628003

Hughes, W., Hillebrandt, P.M., Greenwood, D. and Kwawu, W., 2006. Procurement in the Construction Industry: The Impact and Cost of Alternative Market and Supply Processes. London: Routledge.

Jing, Y., Qiping, S. and Manfong, H., 2009. An overview of previous studies in stakeholder management and its implications for the construction industrynull. Journal of Facilities Management, 7(2), pp.159-75. doi: http://dx.doi.org/10.1108/14725960910952532

Johnston, M., Guaralda, M. and Sawang, S., 2014. Sustainable innovation for Queensland's housing design: A case study. Australasian Journal of Construction Economics and Building, 14(4), pp.11-31. doi: http://dx.doi.org/10.5130/ajceb.v14i4.4146

Loosemore, M., 2014. Innovate or perish? Exploring some of the myths of construction innovation. Australasian Journal of Construction Economics and Building - Conference Series, 2(2), pp.44-55. 
Nadim, W. and Goulding, J.S., 2011. Offsite production: a model for building down barriers: A European construction industry perspective. Engineering, Construction and Architectural Management, 18(1), pp.82-101. doi: http://dx.doi.org/10.1108/09699981111098702

Pan, W., Gibb, A.G.F. and Dainty, A.R.J., 2007. Perspectives of UK housebuilders on the use of offsite modern methods of construction. Construction Management \& Economics, 25(2), pp.183-94. doi: http://dx.doi.org/10.1080/01446190600827058

Richardson, A.J., 2012. Paradigms, theory and management accounting practice: A comment on Parker (forthcoming) "Qualitative management accounting research: Assessing deliverables and relevance". Critical Perspectives on Accounting, 23(1), pp.83-8. doi: http://dx.doi.org/10.1016/i.cpa.2011.05.003

Ritter, T. and Gemunden, H., 2004. The impact of a company's business strategy on its technological competence, network competence and innovation success. Journal of Business Research, 57(5), pp.548-56. doi: http://dx.doi.org/10.1016/S0148-2963(02)00320-X

Saxon, R., 2001. Changing construction culture. In: R.J.S. Spence, S. Macmillan and P. Kirby eds. Interdisciplinary design in practice: Thomas Telford. pp.7-14.

Shahzad, W.M. and Mbachu, J., 2013. Prefabrication as an onsite productivity enhancer: analysis of impact levels of the underlying constraints and improvement measures in New Zealand construction industry. International Journal of Project Organisation and Management, 5(4), pp.334-54. doi: http://dx.doi.org/10.1504/IJPOM.2013.058382

The C. I. E., 2013. Future forecasts: Construction and Property Services Skills 2016-26. CPSISC. Canberra.

Thorpe, D., Ryan, N. and Charles, M.B., 2009. Innovation and small residential builders: an Australian study. Construction Innovation: Information, Process, Management, 9(2), pp.184-200.

Venkatesh, V. and Bala, H., 2008. Technology Acceptance Model 3 and a Research Agenda on Interventions. Decision Sciences, 39(2), pp.273-315. doi: http://dx.doi.org/10.1111/j.1540-5915.2008.00192.x 